\title{
Thermophysical and Mechanical Properties of Granite and Its Effects on Borehole Stability in High Temperature and Three-Dimensional Stress
}

\author{
Wang Yu, ${ }^{1}$ Liu Bao-lin, ${ }^{1}$ Zhu Hai-yan, ${ }^{2}$ Yan Chuan-liang, ${ }^{3}$ Li Zhi-jun, ${ }^{1}$ and Wang Zhi-qiao ${ }^{1}$ \\ ${ }^{1}$ Key Laboratory on Deep Geo-Drilling Technology of the Ministry of Land and Resources, China University of Geosciences, \\ Beijing 100083, China \\ ${ }^{2}$ State Key Laboratory of Oil \& Gas Reservoir Geology and Exploitation, Southwest Petroleum University, Chengdu 610500, China \\ ${ }^{3}$ State Key Laboratory of Petroleum Resource and Prospecting, China University of Petroleum, Beijing 102249, China \\ Correspondence should be addressed to Wang Yu; wangyu203@cugb.edu.cn
}

Received 29 August 2013; Accepted 30 December 2013; Published 20 March 2014

Academic Editors: C. Nah and A. Tonkikh

Copyright (C) 2014 Wang Yu et al. This is an open access article distributed under the Creative Commons Attribution License, which permits unrestricted use, distribution, and reproduction in any medium, provided the original work is properly cited.

\begin{abstract}
When exploiting the deep resources, the surrounding rock readily undergoes the hole shrinkage, borehole collapse, and loss of circulation under high temperature and high pressure. A series of experiments were conducted to discuss the compressional wave velocity, triaxial strength, and permeability of granite cored from 3500 meters borehole under high temperature and three-dimensional stress. In light of the coupling of temperature, fluid, and stress, we get the thermo-fluid-solid model and governing equation. ANSYS-APDL was also used to stimulate the temperature influence on elastic modulus, Poisson ratio, uniaxial compressive strength, and permeability. In light of the results, we establish a temperature-fluid-stress model to illustrate the granite's stability. The compressional wave velocity and elastic modulus, decrease as the temperature rises, while poisson ratio and permeability of granite increase. The threshold pressure and temperature are $15 \mathrm{MPa}$ and $200^{\circ} \mathrm{C}$, respectively. The temperature affects the fracture pressure more than the collapse pressure, but both parameters rise with the increase of temperature. The coupling of thermo-fluid-solid, greatly impacting the borehole stability, proves to be a good method to analyze similar problems of other formations.
\end{abstract}

\section{Introduction}

Deep resources such as oil, gas, and solid mineral have drawn more interest. Generally, the deeper drill is characterized by higher pressure and temperature, which make the drilling and borehole stability harder [1-7]. However, in Mexico Bay, North Sea Basin, Sichuan Basin, and the South Sea of China [8], for example, the gas and oil reservoirs in layers over $200^{\circ} \mathrm{C}$ have been successfully exploited.

When the fluid circles, the upper surrounding rock will be heated; when the fluid ceases to work, however, the lower one will be heated. Balanced by the fluid column pressure and the rock confining pressure $[9,10]$, the heated rock will fail to expand, generating thermal stress as a result [11]. Maury and Guenot claim that the thermal stress contributes most to the instability of the borehole [12]. The outcome they obtained shows that when the temperature of the midhard rock rises up by 1 centigrade, the stress can increase by $0.4 \mathrm{MPa}$, up to $1 \mathrm{MPa}$ for the harder rock as a result. The thermal stress in $25 \mathrm{MPa}$ to $50 \mathrm{MPa}$ is practically common in 4000 meters boreholes. Consequently, the initial borehole stress and the common thermal stress can work together leading to collapse and fracture.

Wang et al.s research [13] shows that the Westerly granite can generate thermal cracking when heated up to $75^{\circ} \mathrm{C}$. And the threshold value of $60 \sim 70^{\circ} \mathrm{C}$ is suggested by Chen et al. [14]. Impacted by hydrostatic stress and thermal cracking, the granite's peak of the permeability, up to $3.5 \times 10 \sim 4 \mathrm{mD} /{ }^{\circ} \mathrm{C}$, to the initial one reaches up to 93 [15]. This indicates that a field characterized by high permeability is developed around the borehole, triggering another stress field. In the borehole, the initial stress, temperature, and the stress field were 


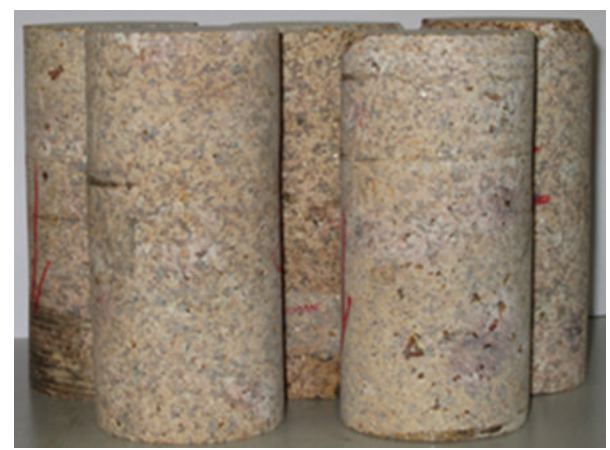

FIGURE 1: Granite samples for testing.

triggered by overlapping the fluid together, which led to the deformation instability and leakage $[9,16,17]$. Consequently, the instability may make the drill stick or damage the casing.

Since the 1980s, in order to dispose the permanent nuclear waste, people began researching the coupling of THM (thermo-hydro-mechanical) [18, 19]. A global International cooperation project named DECOVLEX was established in 1992. Since then, a series of experiments, including modeling, have been conducted and some invaluable outcomes have been obtained as a result [20-24]. At the fourth stage of this project, the aim mainly was to study the mechanics of crystalline rock and the process in which the mechanical and hydraulic properties of the EDZ (excavation damage zone) are transformed. This process can harden or soften the rock [25]. In this paper, the thermal physical and mechanical properties of the granite are developed and researched under high temperature and three-dimensional stress. By utilizing ANASYS-APDL (ANSYS Parameter Design LanguageAPDL) [26, 27], the dynamic evolution equations of elastic modulus, Poisson ratio, uniaxial compressive strength, and permeability of granite with temperature are built and run. The temperature-fluid-stress coupling model to analyze the granite's stability is established and simulated to figure out the temperature's influence on collapse pressure, fracture pressure, and stress near the borehole, which can provide theoretical guidance for borehole stability and safety drilling in granite formations.

\section{Thermophysical and Mechanical Properties}

2.1. Overview of Experiment. The sample, obtained from a 1000 meter deep borehole in Mount Yan, North China, is about $100 \mathrm{~mm}$ with a diameter of $50 \mathrm{~mm}$. The density is about $2.54 \mathrm{~g} / \mathrm{cm}^{3}$. TAW-1000 deep pore pressure servo experimental system was employed to test the sample. It consists of quartz, feldspar, and hornblende. All the samples were processed on the basis of Chinese national standard of GB50128-94 (shown in Figure 1). In order to avoid being contaminated by the hydraulic oil, we encapsulated the sample with a $3 \mathrm{~mm}$ thickness hot pyrocondensation pipe.

The experiments were conducted in a $1000^{\circ} \mathrm{C}$ electrothermal furnace whose space is $300 \times 200 \times 120 \mathrm{~mm}$. The samples were placed at the center of the furnace, to whose front and

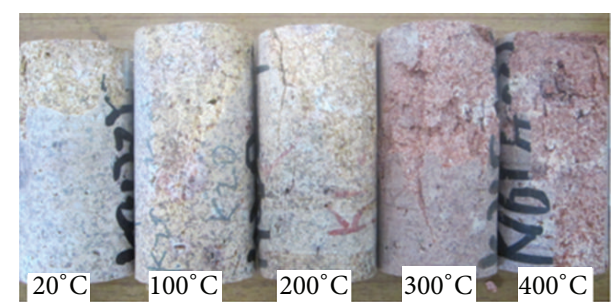

FIGURE 2: Rock samples correlation under different temperature.

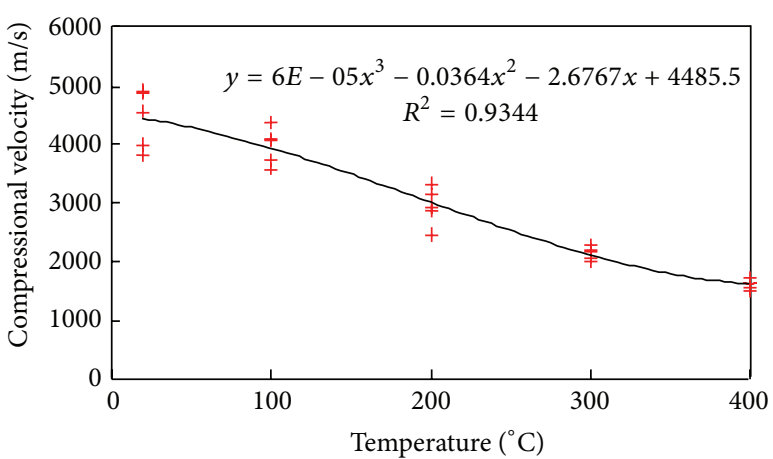

FIGURE 3: Longitudinal wave velocity variation curve with temperature in granite.

rear it is about $3 \mathrm{~mm}$ far from the sample. All the samples were divided into 5 groups, with each was heated to room temperature, $100^{\circ} \mathrm{C}, 200^{\circ} \mathrm{C}, 300^{\circ} \mathrm{C}, 400^{\circ} \mathrm{C}$ and insulated for 2 hours, respectively. Compared with the original sample in Figure 2, these heated to $300^{\circ} \mathrm{C}$ and $400^{\circ} \mathrm{C}$ is dark red, owing to the $\mathrm{Fe}^{3+}$ transformed from $\mathrm{Fe}$.

2.2. Longitudinal Wave Velocity Characteristics. Figure 3 plots the link between longitudinal wave velocity and the temperature. The curve shows that the speed varies inversely with the temperature. This can be accounted for as follows: (I) as free water inside the rock evaporates, the pore becomes bigger; (II) when the temperature increases, the thermal stress will be triggered between minerals, due to their different coefficients of thermal expansion and anisotropy, generating new fractures or expanding the old.

\subsection{Uniaxial Compression Tests}

2.3.1. Uniaxial Strength and Strain. Figure 4 plots the link between temperature and uniaxial strength. It shows that the threshold temperature is $200^{\circ} \mathrm{C}$, in accordance with the result obtained from Figure 5. Below $200^{\circ} \mathrm{C}$, the sample mainly undergoes brittle fracture, specially divided into compacting and linear elastic phases. On the other hand, over $400^{\circ} \mathrm{C}$, the sample mainly undergoes the shear and tensile fractures.

Below 200 centigrade, the peak stress increases slowly but rapidly when it is over 200 centigrade. It shows that the threshold temperature is 200 centigrade, which accords with the outcome obtained from the link between the temperature and the uniaxial strength. 


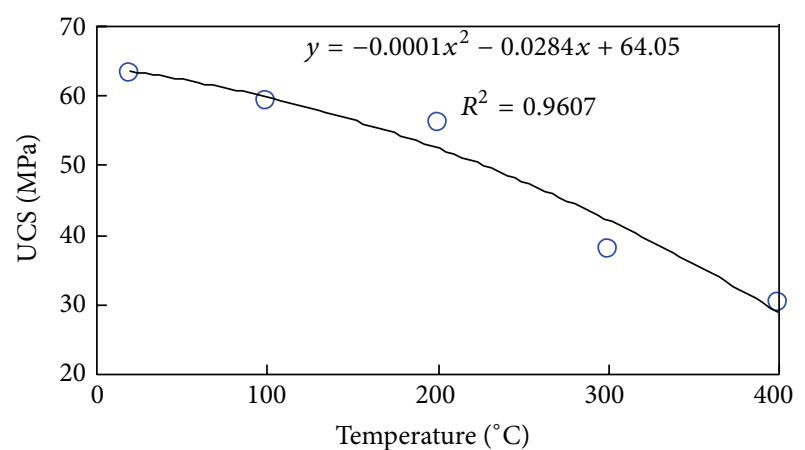

FIGURE 4: Uniaxial strength variation curve with temperature in granite.

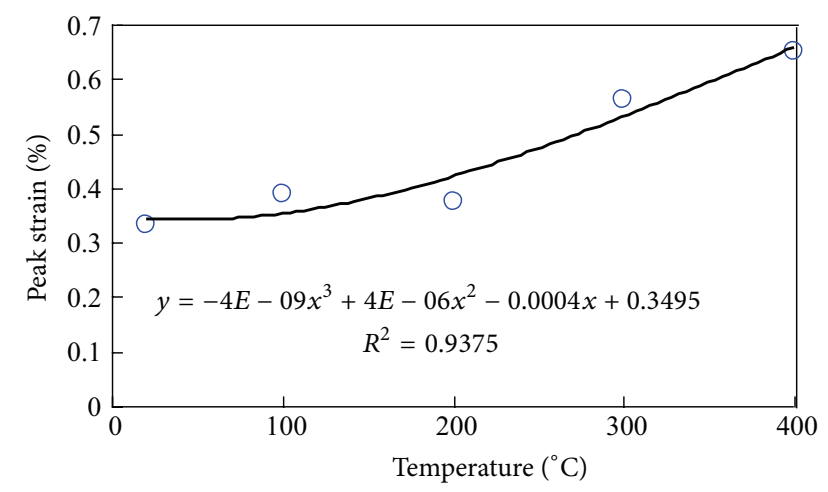

FIGURE 5: Peak strain variation curve with temperature in granite.

2.3.2. Elasticity Parameters of the Sample. The thermal damage is introduced to reflect the fluctuation of the elastic modulus of the samples before and after the heating the sample. The thermal stress will be produced between different mineral compositions due to the temperature change [28]. The thermal damage is calculated as follows:

$$
D(T)=1-\frac{E_{(T)}}{E_{(0)}} .
$$

The elastic modulus decreases with the increase of the temperature. Additionally, $e$ the relationship between the elastic modulus and temperature is fitted by the data, and its fitting formula is $E=-0.0145 T+29.997$, with a goodness of 0.955 .

Figure 6 displays the increase of thermal damage after the sample was heated. As same as aforementioned, the threshold temperature obtained from the $D-T$ curve is also 200 centigrade. When the temperature is from 0 centigrade to 100 centigrade and over 200 centigrade, the thermal damage of the sample is increasing while the thermal damage is unchanged from 100 centigrade to 200 centigrade.

The Poisson ratio is characterized by polymeric. As shown in Figure 7, with the increasing of the temperature, the Poisson ratio of the granite samples is more and more mounting. The proportion between Poisson ratio and temperature is mainly accounted for two reasons: (I) the increase of the temperature leads to the changes of the sample's interior

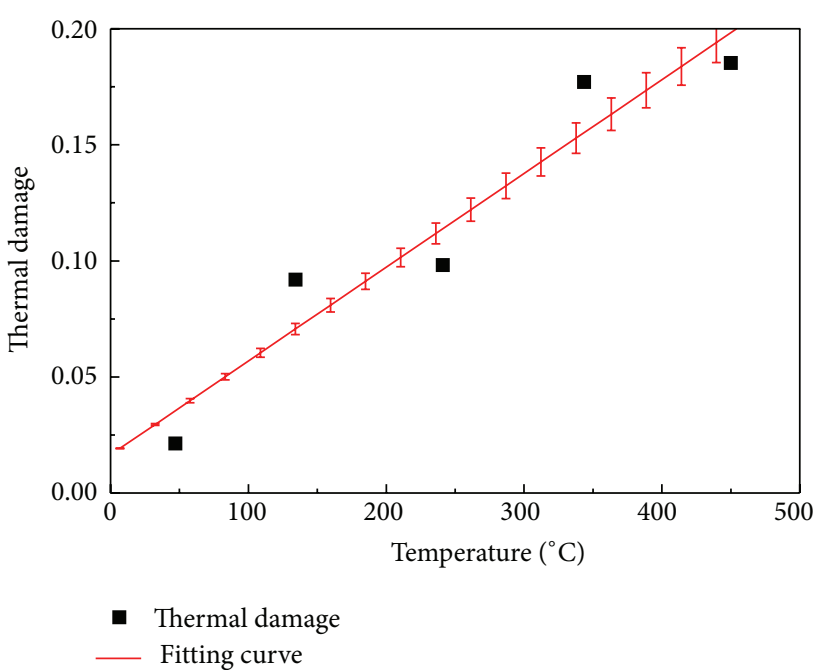

FIgURE 6: Thermal damage curve under different temperatures in granite.

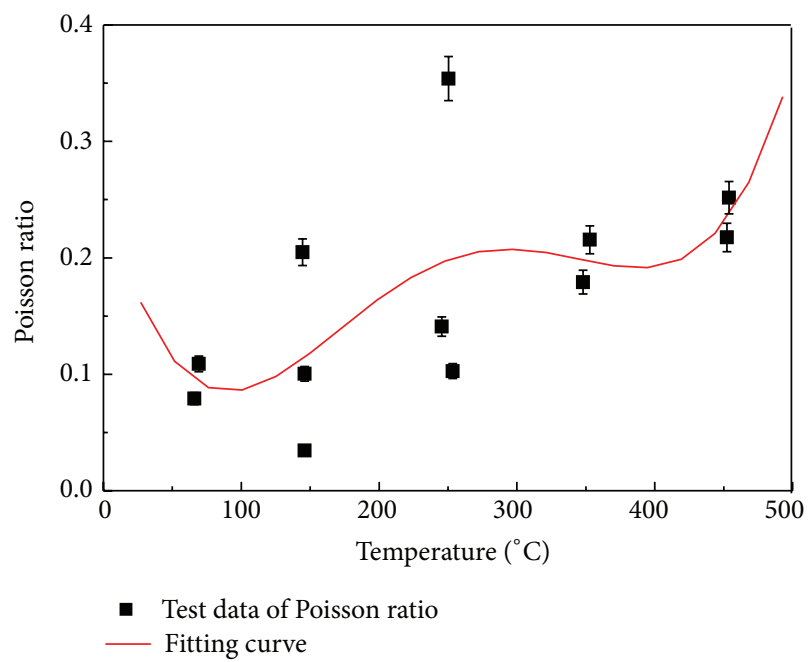

FIGURE 7: Poisson ratio curve under different temperatures in granite.

structure, the water content, and the porosity; (II) and the temperature and stress are beyond the sample's elasticity.

2.3.3. Damage States of Samples. The sample was experimentally damaged under uniaxial pressure in three ways as shown in Figure 8: (I) under room temperature, the sample undergoes the brittle fractures developing along the axial direction. (II) Under $100-200^{\circ} \mathrm{C}$, the sample undergoes the shear fracture. If loaded, the softer part would be damaged without losing its bearing capacity. (III) Under $300-400^{\circ} \mathrm{C}$, being sheared and tensioned, the sample undergoes the column fractures. 


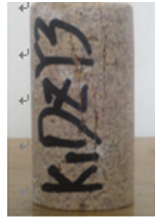

$20^{\circ} \mathrm{C}$

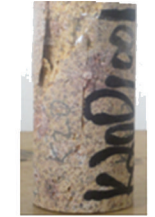

$100^{\circ} \mathrm{C} \leq \mathrm{T} \leq 200^{\circ} \mathrm{C}$

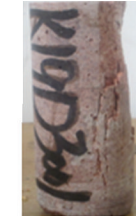

$300^{\circ} \mathrm{C} \leq \mathrm{T} \leq 400^{\circ} \mathrm{C}$
FIGURE 8: Ordinary damage states under uniaxial pressure.

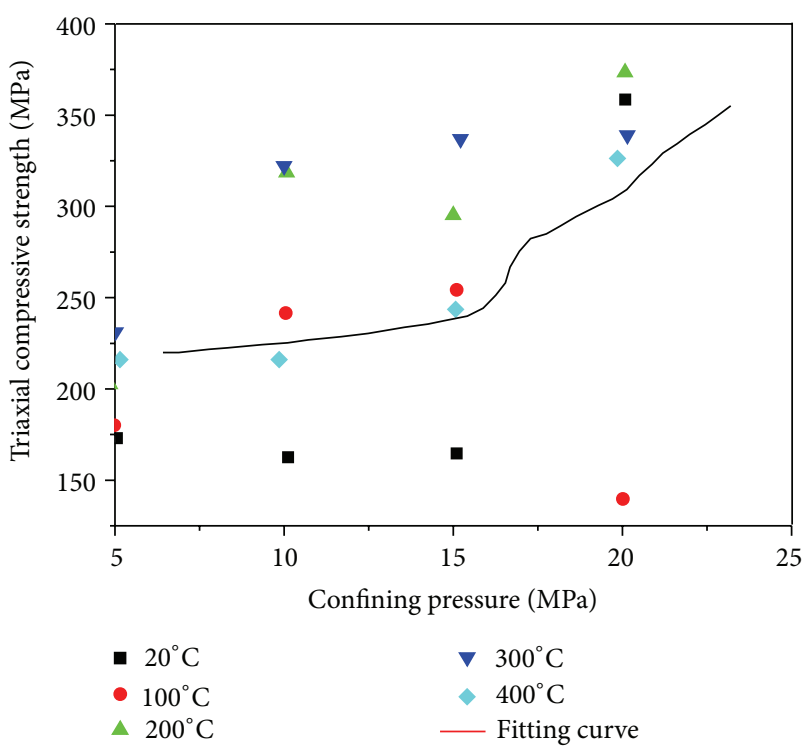

FIgURE 9: Triaxial compressive strength curve with confining pressure and temperature.

\subsection{Triaxial Compression Tests}

2.4.1. Mechanical Properties with Different Confining Pressure. Figure 9 displays the link between triaxial compressive strength and confining pressure. It shows that as the confining pressure rises, the triaxial compressive strength virtually and nonlinearly increases. With $R=0.996$, the nonlinear link can be expressed as

$$
\sigma_{s}=0.834 \sigma_{w}^{2}-14.05 \sigma_{w}+269.65
$$

The link between elastic modulus and confining pressure was displayed in Figure 10. The elastic modulus changed the same as the confining pressure except $20 \mathrm{MPa}$. The threshold pressure is $15 \mathrm{MPa}$. The elastic modulus can be expressed as

$$
E=-0.095 \sigma_{w}^{2}+3.085 \sigma_{w}+8.775 .
$$

2.4.2. Mechanical Properties with Different Temperatures. Figures 11, 12, and 13, respectively, present the influence exerted by a given temperature on triaxial compressive strength, axial strain at failure, and elastic modulus, which are characterized by discreteness. The three figures confirm that $200^{\circ} \mathrm{C}$ is the threshold temperature and pressure.

2.4.3. Damage States of Samples. Tested by deep pore pressure servo experimental system, the samples were broken by

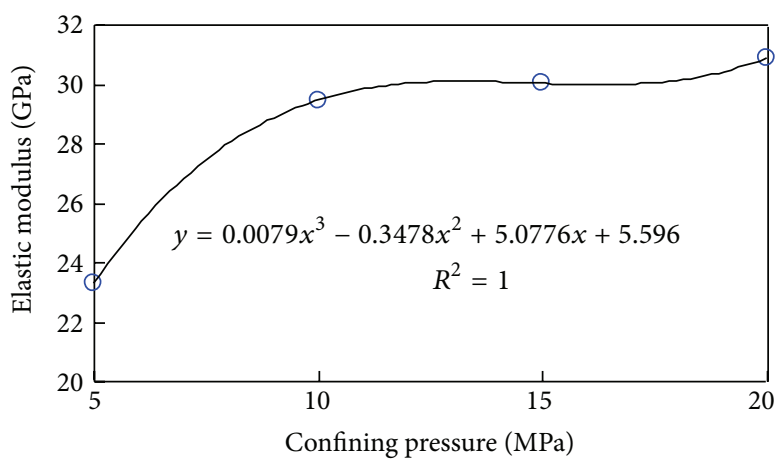

FIGURE 10: Relationship between elastic modulus and confining pressure under $300^{\circ} \mathrm{C}$.

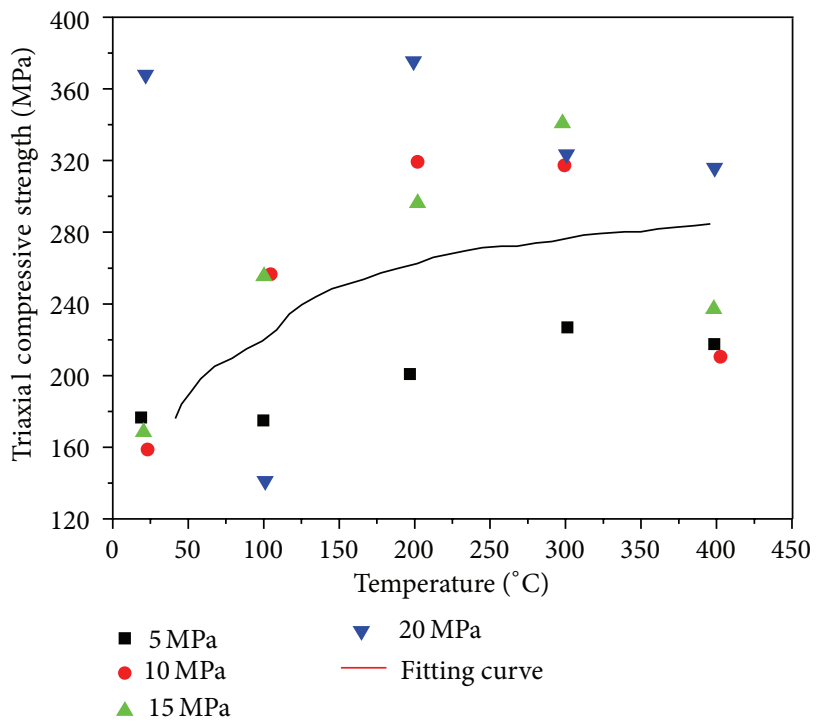

FIGURE 11: Relationship between triaxial compressive strength and temperature with constant confining pressure.

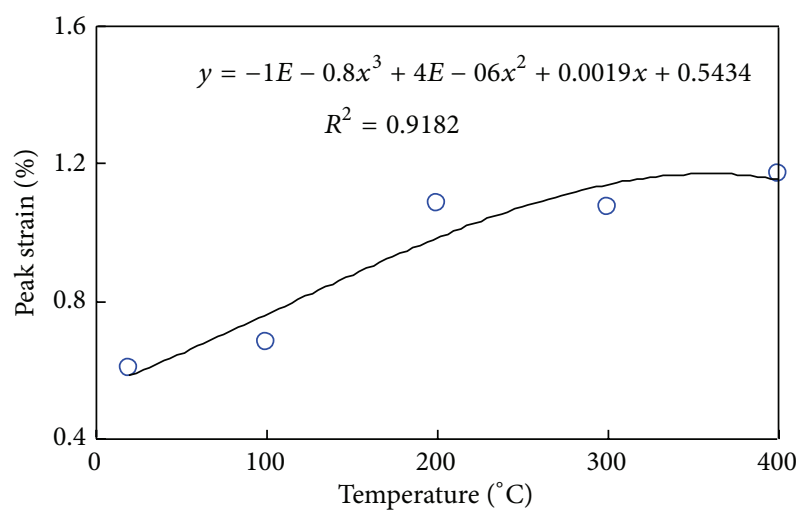

FIGURE 12: Peak strain variation curve with temperature with constant confining pressure. 


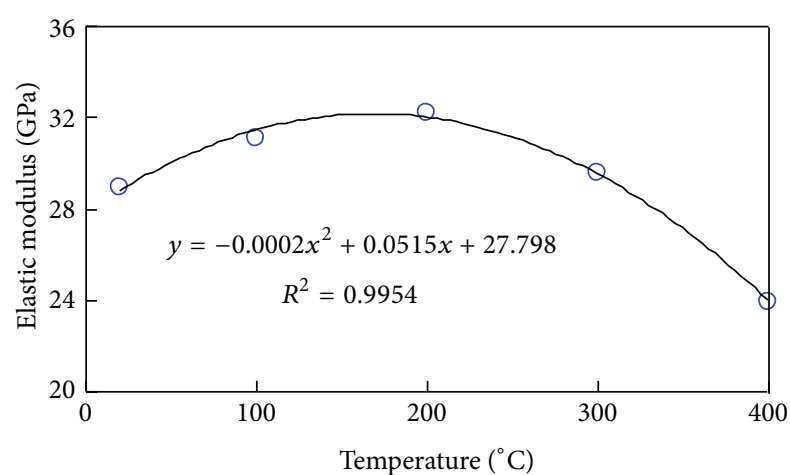

FIGURE 13: Elastic modulus variation with temperature with constant confining pressure.

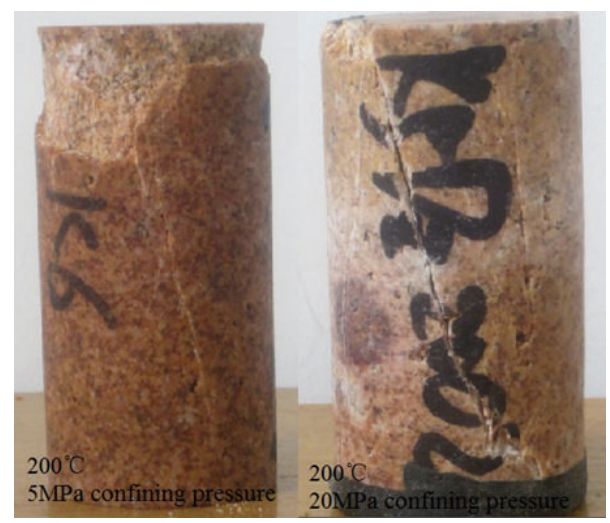

FIGURE 14: Ordinary damage states under triaxial stress.

two ways: (I) when heated to $200^{\circ} \mathrm{C}$ or lower, the sample undergoes the brittle fracture. However, when the confining pressure increased to $20 \mathrm{MPa}$, the shear and tension fracture dominated. (II) When heated over $200^{\circ} \mathrm{C}$, the sample undergoes the compression shear and fracture (Figure 14).

2.5. Permeability Effected by Temperature. The permeability was measured by TAW-1000 deep pore pressure servo experimental system. The sample was enwrapped by a $3 \mathrm{~mm}$ thickness hot pyrocondensation pipe. Pressed around by $20 \mathrm{MPa}$, the sample's one end was ventilated by $\mathrm{N}_{2}$ and a highly precise gas flowmeter was installed at its other end. Figure 15 indicates that the threshold temperature is $200^{\circ} \mathrm{C}$. The thermal fracture improves the permeability.

\section{Finite Element Simulation and Experiment}

3.1. Basic Equations. Adopting the definition of Biot's effective stress, the relationship between effective stress and total stress is

$$
\sigma^{\prime}=\sigma+p_{w} I
$$

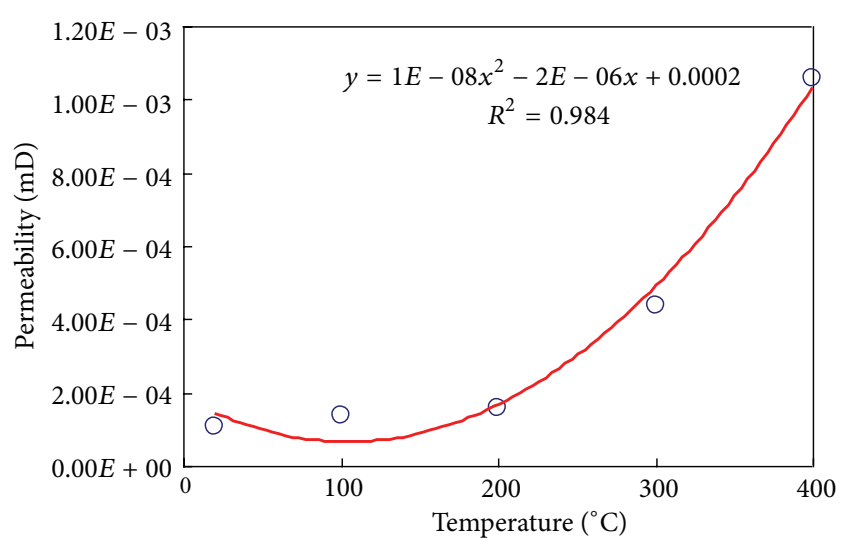

FIGURE 15: Permeability curve under different temperatures in granite.

The mass conservation equation of fluid is

$$
\begin{gathered}
\frac{\partial}{\partial x_{i}}\left[\frac{\rho_{1} k_{1 i j}}{\mu_{1}}\left(\frac{\partial p_{1}}{\partial x_{j}}+\rho_{1} g_{j}\right)+\rho_{1} k_{1 T i j} \frac{\partial T}{\partial x_{j}}\right] \\
=n \frac{\partial p_{1}}{\partial t}+\rho_{1} \frac{d n}{d t} .
\end{gathered}
$$

The energy conservation equation of solid is

$$
\frac{\partial}{\partial t}\left[(1-n) \rho_{s} \cdot C_{s} \cdot \Delta T\right]=-\frac{\partial q_{s i}}{\partial x_{j}}+Q_{s} .
$$

The energy conservation equation of fluid is

$$
\begin{gathered}
\frac{\partial}{\partial t}=n \cdot \rho_{1} \cdot C_{1} \cdot \Delta T=-\frac{\partial}{\partial x_{j}}\left(q_{1 i}+q_{1 i}^{c}\right), \\
q_{1 i}=-\lambda_{1 i j} n \frac{\partial T}{\partial x_{j}} q_{1 i}, \\
q_{1 i}^{c}=\rho_{1} \cdot C_{1} \cdot \Delta T \cdot v_{1 i}^{r} \\
=-\rho_{1} \cdot C_{1} \cdot \Delta T \cdot\left[\frac{k_{1 i j}}{\mu_{1}}\left(\frac{\partial p_{1}}{\partial x_{j}}+\rho_{1} \cdot g_{j}\right)+k_{1 T i j} \frac{\partial T}{\partial x_{j}}\right] .
\end{gathered}
$$

Assume that at any point inside the solid phase and liquid phase has the same temperature, the total energy conservation equation [29] can be expressed as

$$
\begin{gathered}
\frac{\partial}{\partial t}\left[(1-n) \rho_{s} \cdot C_{s} \cdot \Delta T+n \cdot \rho_{1} \cdot C_{1} \cdot \Delta T\right] \\
=-\frac{\partial q_{s i}}{\partial x_{j}}\left(q_{m i}+q_{1 i}^{c}\right)+Q_{s} .
\end{gathered}
$$

The total heat flux density of rock and fluid can be expressed as

$$
q_{m i}=q_{s i}+q_{1 i}=-\left[\lambda_{s i j} \cdot(1-n)+\lambda_{1 i j} \cdot n\right] \cdot \frac{\partial T}{\partial x_{j}} .
$$


Based on mixture theory, the equivalent thermal conductivity can be defined; namely,

$$
\lambda_{m i j}=\lambda_{s i j} \cdot(1-n)+\lambda_{1 i j} \cdot n .
$$

According to the principle of virtual displacement, the whole equilibrium differential equations in solution domain can be represented as

$$
\int_{\Omega} \delta \cdot \varepsilon^{T} \cdot \sigma^{\prime} \cdot d \Omega-\int_{\Omega} \delta \cdot u^{T} \cdot b \cdot d \Omega-\int_{\Omega} \delta \cdot u^{T} \cdot t \cdot d s=0 .
$$

We take the effective stress of rock skeleton equation into (11), and according to the mass conservation equation of the fluid and fluid-solid overall energy conservation equation to form the control equations under the heat-flow-solid coupling. The finite element discretization method can be used to solve the equations' system after it has been transferred to the equivalent credits' weak formulation.

3.2. Dynamic Evolution Equations. Based on indoor experiment of this study paper, it was found that the dynamic evolution equations of elastic modulus, Poisson ratio, uniaxial compressive strength, and permeability of Granite with temperature can be represented as

$$
\begin{gathered}
E=-0.0145 T+29.977, \\
v=0.0004 T+0.1185, \\
\mathrm{UCS}=-0.0001 T^{2}-0.0284 T+64.05, \\
K=1 E-08 T^{2}-2 E-06 T+0.0002 .
\end{gathered}
$$

3.3. Engineering Application Example. The paper uses the ANSYS secondary development function of the fluid-solid interaction module and temperature-structure coupling calculation module for the solver, according to the decoupling method; firstly we do numerical calculation of the graniteborehole temperature field and then put the results into ANSYS fluid-solid interaction of calculation module.

The units' segmentation of temperature field and the units' segmentation of flow-solid coupling calculation is the same, such that the plane-strain problems use four-node units. The dynamic evolution of elastic modulus, Poisson ratio, uniaxial compressive strength, and permeability of granite using secondary development of the ANSYS parametric design language (ANSYS Parameter Design LanguageAPDL) to achieve. Firstly, to extract the temperature of the unit in the process of thermal analysis calculation, and modify the unit parameters of the thermal and mechanical properties, to form Loop iteration control process, and realize the Granite-borehole temperature coupling.

The stimulation was performed on a one-fourth sample of symmetry. The sample was divided into 612 four-point units in Figure 16. We compared the finite element calculation results with the analytical solutions of Marshall and Bentsen [30] to verify the reliability of the model adopted in this paper. According to the relationship of the rock mechanics of granite

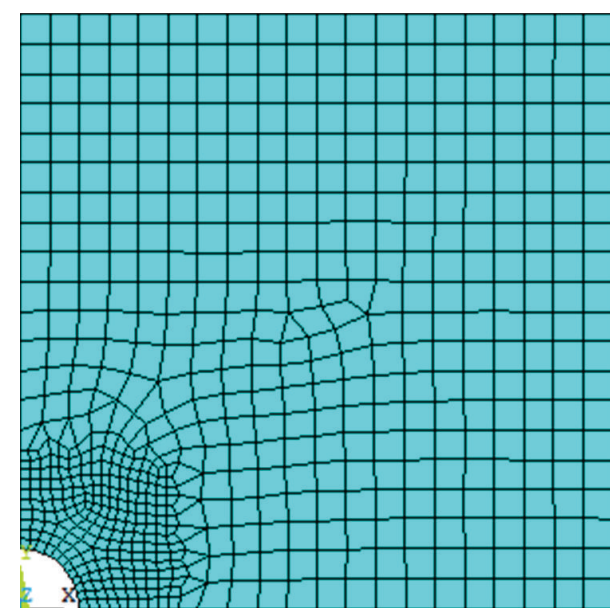

FIGURE 16: Plane model of borehole.

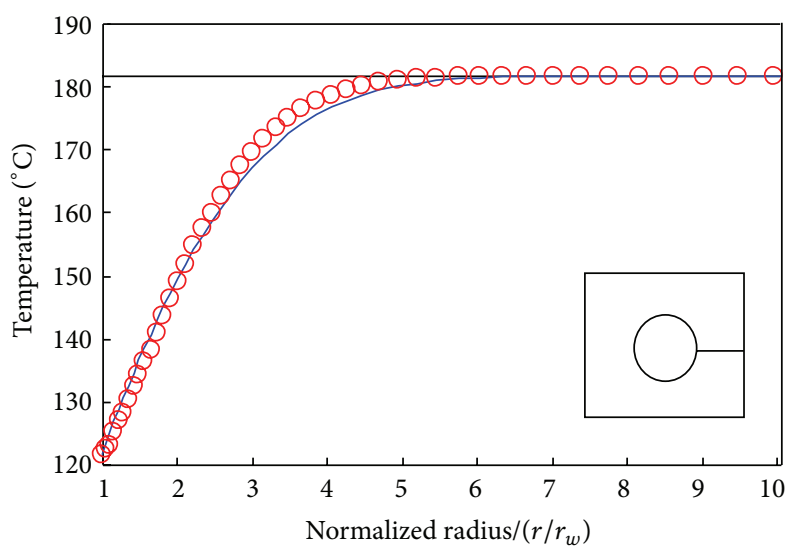

Original formation temperature
Calculation result

FIGURE 17: Temperature distribution near borehole.

that tested indoor and confining pressure, then converted it to the parameters under the condition of confining pressure in this area and applied it to this model, finally the temperature distribution of the borehole surrounding rock was acquired. Figure 17 illustrated the temperature distribution of the borehole surrounding rock after 8-hour drilling, where the finite element calculation results matched borehole with the analytical solutions. The of the wall and surrounding rock decreased gradually along with the decreasing of drilling fluid temperature, besides the thermal stress of the wall down to the minimum. With the increasing of distance from the borehole, the formation temperature increased gradually until it reached the original formation temperature. The formation that far away from the wall approximately equal five times the boreholebore radius, its internal temperature almost no change, and stayed at the original formation temperature $182^{\circ} \mathrm{C}$.

The influence that impacted the granite strata borehole wall stability in the temperature field, the stress field, and the seepage field mainly was exerted by changing the stress 


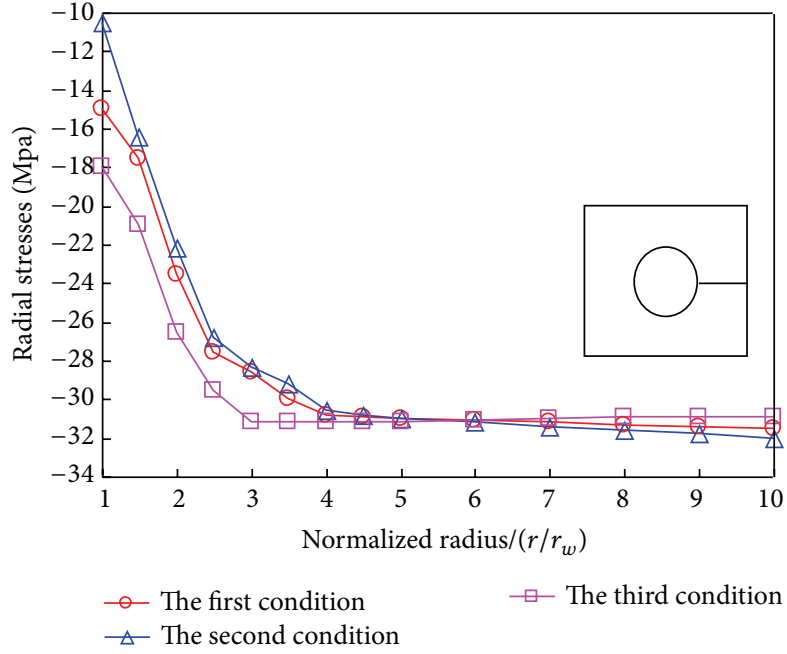

FIGURE 18: Distribution of the radial stress in borehole under different conditions.

state of the borehole [31]. As a result, the original formation of equilibrium was destroyed so that the stress concentration produced around the borehole easily brought up the sidewall instability. The below three kinds of conditions were accounted for to explain the influence on the sidewall stress brought by interconnection. Firstly, do not consider the interconnection of the temperature field and the stress field but consider the interconnection of the seepage field and the stress field. Secondly, do not consider the interconnection of the seepage field and the stress field, but consider the interconnection of the temperature field and the stress field. Thirdly, consider the interconnection of the temperature field and the stress field and the seepage field simultaneously.

3.3.1. Stress in Borehole. Figures 18 and 19 display the distribution of radial and tangential stresses peripheral to the borehole. It indicates that temperature and percolation accordantly influence the stress. The minimum stress occurs near the borehole; on the other hand, the samples virtually undergo the same stress under the above three conditions in the further field.

3.3.2. Borehole Stability Effected by Temperature. The shear fracture of the rock, subject to Mohr-Coulomb, expressed by the main stress is described as

$$
\sigma_{1}=\sigma_{3} \tan ^{2}\left(\frac{\pi}{4}+\frac{\varphi}{2}\right)+2 C \tan \left(\frac{\pi}{4}+\frac{\varphi}{2}\right) .
$$

The shear fracture will occur when the maximum and minimum effective principal stresses are beyond the breaking strength of the rock.

The layer will collapse when the tangential effective stress is over the tensile strength of the rock:

$$
\sigma_{\theta}-\alpha P_{P}=-S_{t} .
$$

The stress distribution is calculated on the basis of finite element. Considering the shear failure and tensile failure, the

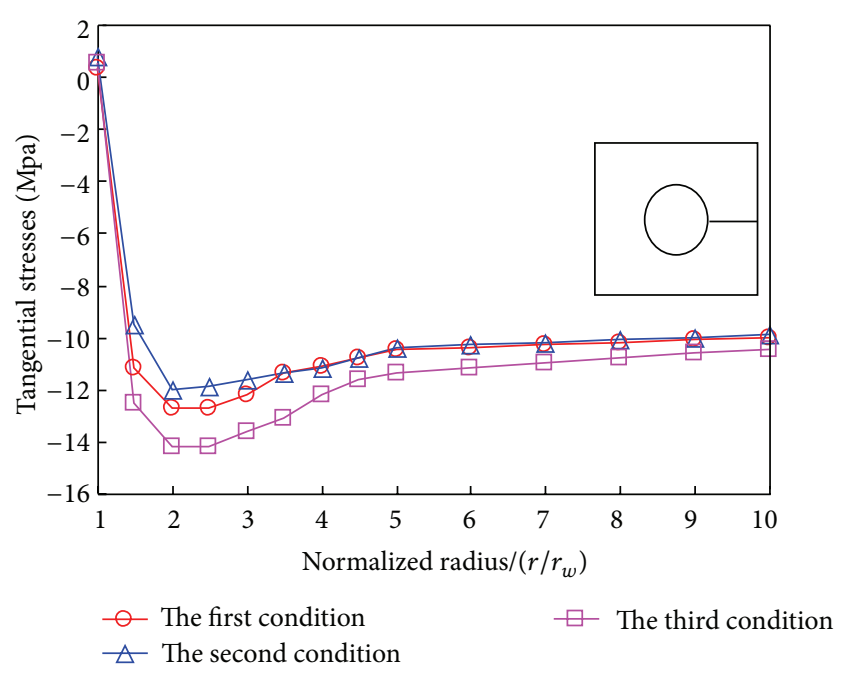

FIGURE 19: Distribution of the tangential stress in borehole under different conditions.

collapse pressure and tensile pressure are calculated. Suppose the uniaxial compressive strength is subject to temperature. Based on Griffith,

$$
\sigma_{c}=(8 \sim 12) S_{t} .
$$

The variations of collapse pressure and fracture pressure with temperature increase and decrease are shown in Figures 20 and 21 , respectively.

3.3.3. Borehole Stability Affected by Permeability. A filter cake can be developed as the fluid seeps through the permeable reservoir. In this case where the fluid will be constrained, the pore pressure is not equal to the drilling fluid column pressure.

Figure 22 plots the link between the permeability coefficient and the collapse and fracture pressure. The fact that the value by which the fracture decrease is bigger than the collapse pressure increase indicates that the permeability coefficient influences the fracture pressure more. Consider

$$
\delta=\frac{\left(p_{w}-p_{o}\right)}{\left(p-p_{o}\right)}, \quad 0 \leq \delta \leq 1 .
$$

\subsubsection{Stability in Deviated Borehole}

(I) Collapse Pressure in Deviated Borehole. Under different conditions, in Figures 23, 24, and 25 the distributions of the collapse pressure were performed.

Suppose north-south and east-west as the directions along which the horizontal maximum and minimum stresses developed, respectively. It can be concluded that the seepage can cut the maximum and add the minimum collapse pressures; the decrease of the temperature, however, leads to the increase of the maximum and minimum collapse pressure. What is more, Figure 25 shows that the minimum collapse pressure can reach the smallest, with the maximum 


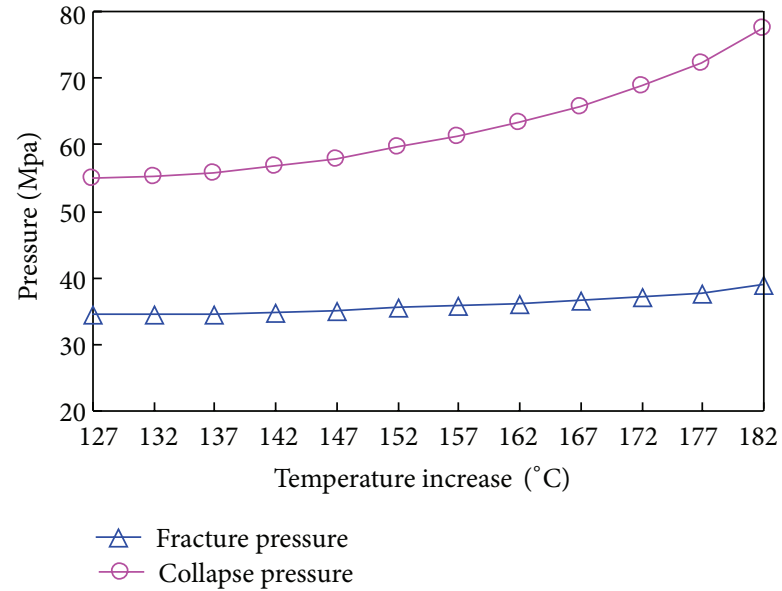

FIGURE 20: Variation of collapse pressure and fracture pressure with temperature increase.

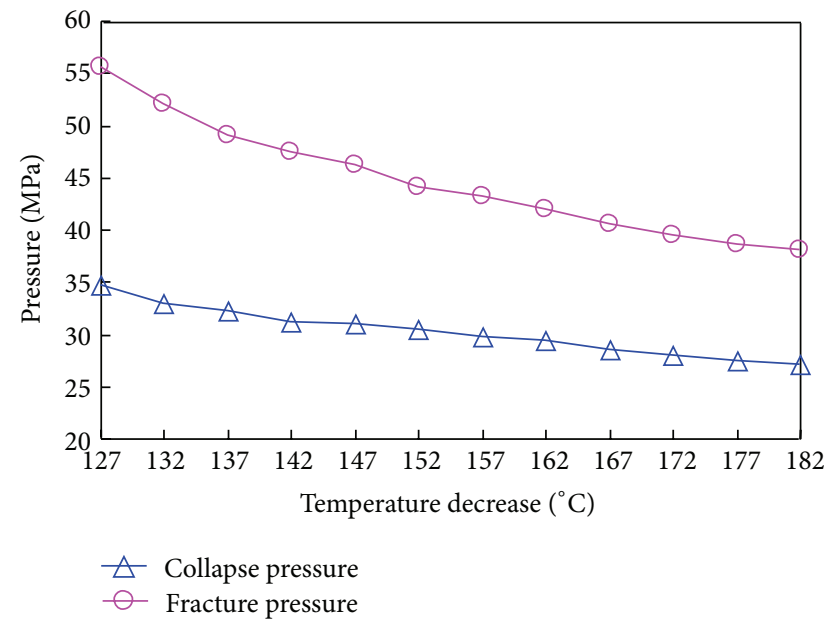

FIGURE 21: Variation of collapse pressure and fracture pressure with temperature decrease.

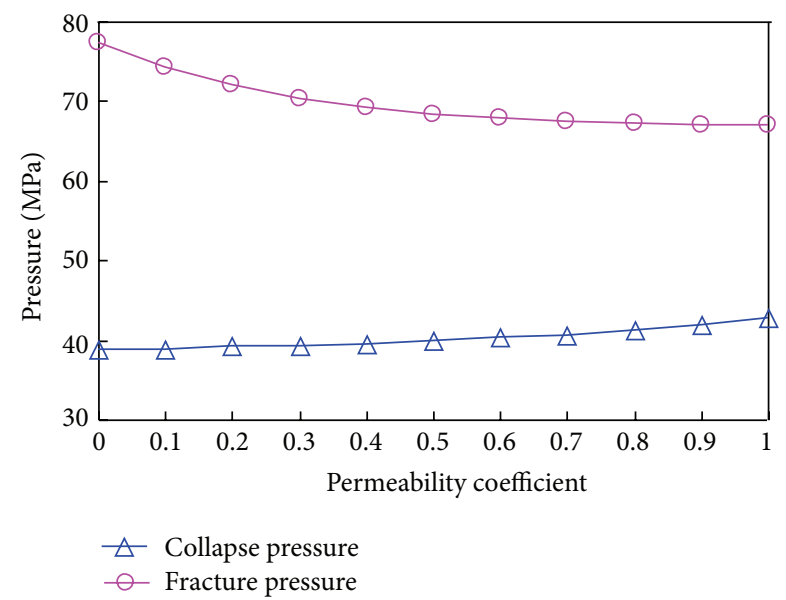

FIGURE 22: Variation of collapse pressure and fracture pressure with permeability.

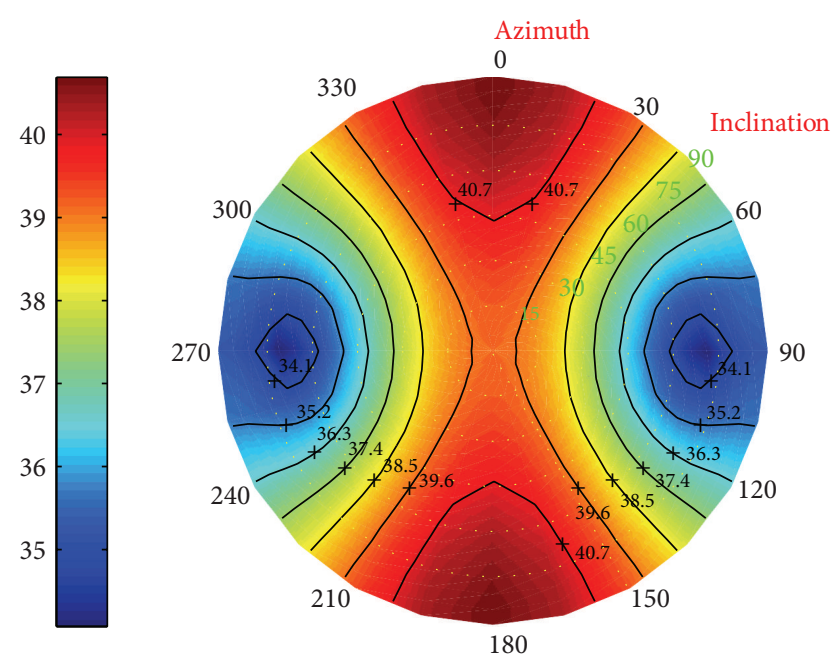

FIGURE 23: Risk distribution of collapse pressure when permeability coefficient is 0.5 .
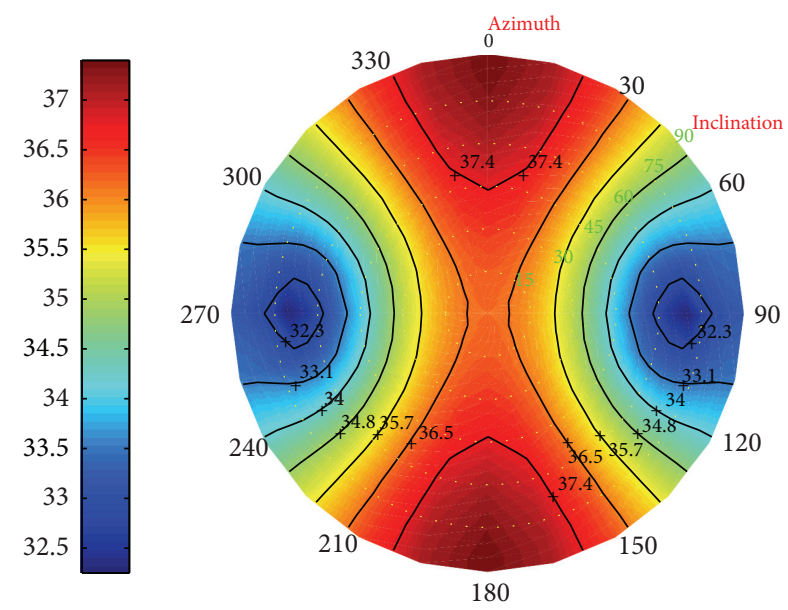

FIGURE 24: Risk distribution of collapse pressure when temperature drop is $25^{\circ} \mathrm{C}$.

ranking the middle. Without considering the fluid, the result will be below the prediction; on the other hand, without considering the temperature, the result will be beyond the prediction.

(II) Fracture Pressure in Deviated Borehole. Additionally, the distribution of the fracture pressure was performed in Figures 26, 27, and 28.

When drilling along the direction of the minimum principal stress, the fracture pressure reached the biggest, increasing the upper boundary of the fluid's density. It shows that the wider the window of the fluid is, the safer the drilling is. When drilling along the direction of the maximum stress, the fracture pressure reaches the minimum. As a result, it is suggested that in order to ensure the borehole stability, we should drill along the direction of the maximum stress. If the fracture pressure is beyond the expectation, the sloughing formation will be developed. 


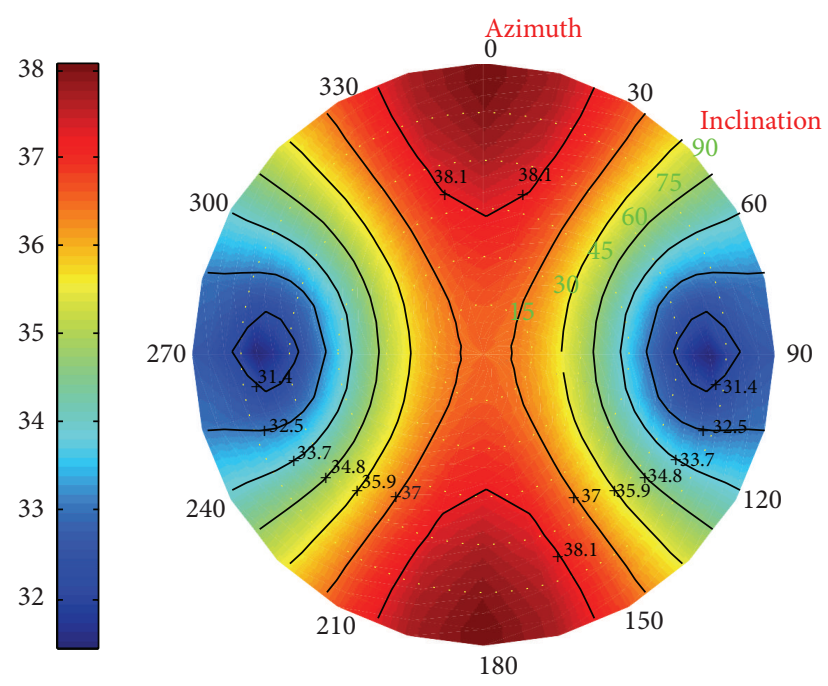

FIGURE 25: Risk distribution of collapse pressure under coupling of thermo-fluid-solid.

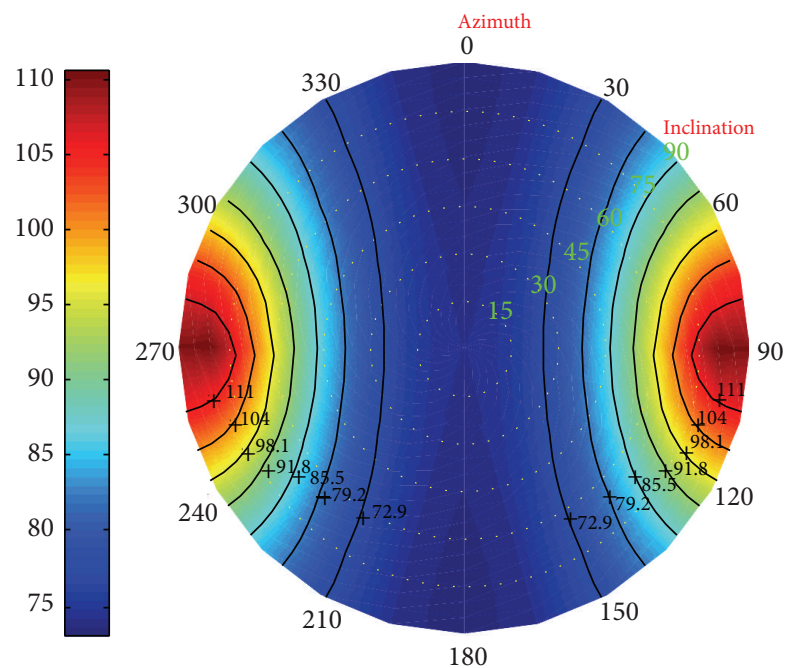

FIGURE 26: Risk distribution of fracture pressure when permeability coefficient is 0.5 .

\section{Conclusion}

(1) It is shown that the threshold temperature of strength and elastic modulus of granite are both 200 centigrade. Below this, the sample mainly undergoes the brittle fracture and the rupture surface is along the axial direction under small confining pressure, while shear compression failure is the main state when the confining pressure is over $20 \mathrm{MPa}$. Above 200 centigrade, the damage modes are mixing shear compression and brittle fracture failure, and shear compression failure is positively correlated with the increasing of confining pressure and temperature.

(2) The compressional wave velocity, elastic modulus, and uniaxial compression strength will decrease as
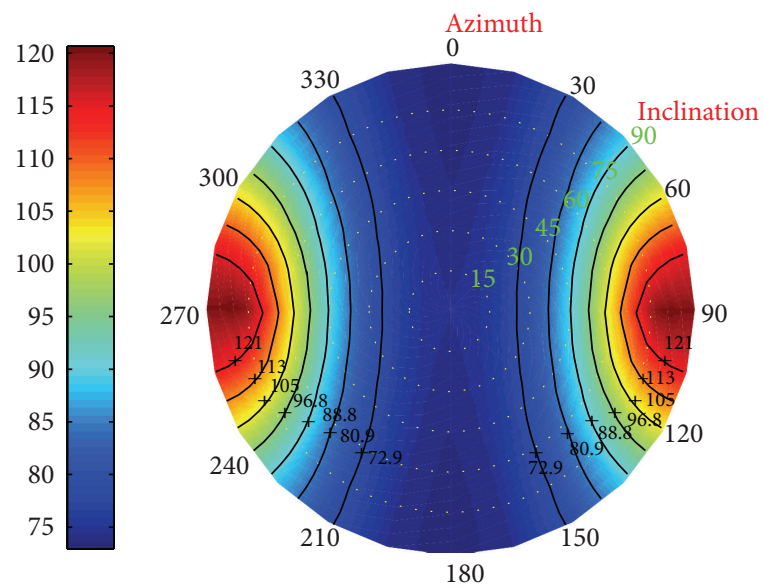

FIGURE 27: Risk distribution of fracture pressure when temperature drop is $25^{\circ} \mathrm{C}$.

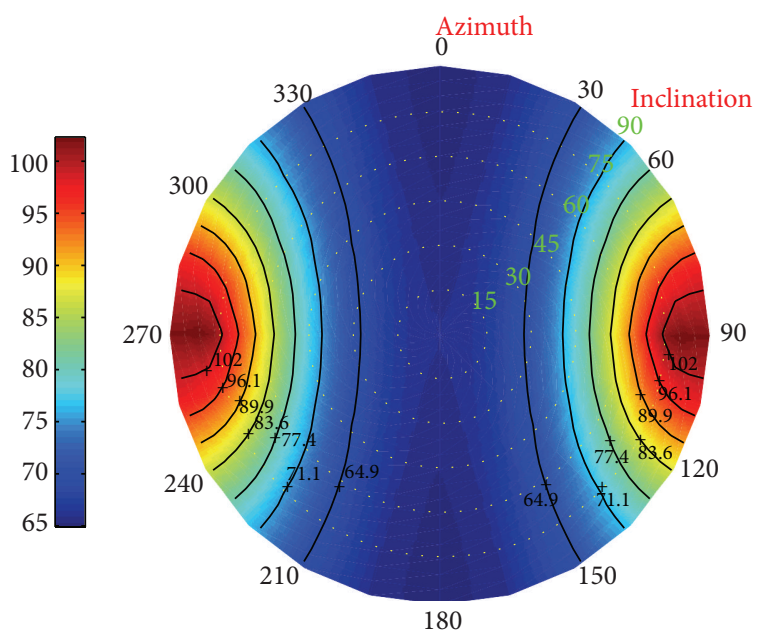

FIGURE 28: Risk distribution of fracture pressure under coupling of thermo-fluid-solid.

the temperature rises. Additionally, when the temperature is given, the elastic modulus and strength will increase as the surrounding pressure rises. The threshold pressure and temperature are $15 \mathrm{MPa}$ and $200^{\circ} \mathrm{C}$, respectively. The threshold thermal fracture temperature is $200^{\circ} \mathrm{C}$. The permeability will dramatically increase with the rise of temperature up to $10^{-3} \sim$ $10^{-4} \mathrm{mD}$.

(3) The coupling borehole stability model of thermofluid-solid is developed by the ANASYS-APDL. The dynamic evolution equations of elastic modulus, Poisson ratio, uniaxial compressive strength, and permeability of granite with temperature are built and run. The results show that the radical stress and tangential stress are greatly different in full coupling model and in other physical field models. The results simulated by full coupling model are more precise and reliable than other models. 
(4) The temperature affects the fracture pressure more than the collapse pressure. In order to avoid losing fluid, we suggest lowering the fluid's density when the temperature of the borehole wall decreases. As for the permeability, its rise leads to the decrease of the fracture pressure but increase of the collapse pressure, which indicates that the low-density fluid is better.

(5) The seepage degrades the upper limit of collapse pressure and heightens the lower limit. The fall of temperature heightens both upper and lower limits of collapse pressure in borehole. As a result, in order to accurately predict the collapse pressure, the seepage and temperature are supposed to be taken into account.

\section{Nomenclature}

$D(T)$ : Thermal damage coefficient

T: $\quad$ Temperature, ${ }^{\circ} \mathrm{C}$

$E_{(T)}$ : Elastic modulus at $T^{\circ} \mathrm{C}, \mathrm{GPa}$

$E_{(0)}$ : Elastic modulus at $20^{\circ} \mathrm{C}, \mathrm{GPa}$

E: $\quad$ Elastic modulus, GPa

$R: \quad$ Goodness of fit

$\sigma_{s}: \quad$ Triaxial compressive strength, $\mathrm{MPa}$

$\sigma_{w}: \quad$ Confining pressure, $\mathrm{MPa}$

$\sigma^{\prime}$ : $\quad$ Matrix of effective stress, $\mathrm{MPa}$

$\sigma: \quad$ Matrix of total stress, MPa

I: $\quad$ Second-order unit tensor

$p_{w}$ : Absolute value of pressure, $\mathrm{MPa}$

$n$ : $\quad$ Porosity

$k_{1 i j}$ : Permeability coefficient of fluid

$k_{1 T i j}$ : Velocity of flow coefficient affected by temperature

$\mu_{1}: \quad$ Viscosity coefficient of fluid

$\rho_{1}: \quad$ Density of fluid, $\mathrm{kg} / \mathrm{m}^{3}$

$p_{1}$ : Hydraulic pressure, $\mathrm{Pa}$

$g_{j}: \quad$ Acceleration of gravity of fluid, $\mathrm{m} / \mathrm{s}^{2}$

$C_{s}: \quad$ Specific heat capacity, $\mathrm{J} / \mathrm{kg} \cdot \mathrm{K}$

$\rho_{s}$ : Density of rock, $\mathrm{kg} / \mathrm{m}^{3}$

$q_{s i}: \quad$ Heat flux density of rock, $\mathrm{J} / \mathrm{m}^{2} \cdot \mathrm{s}$

$Q_{s}: \quad$ Energy conversion coefficient, $\mathrm{J} / \mathrm{m}^{3} \cdot \mathrm{s}$

$C_{1}$ : $\quad$ Specific heat capacity of fluid, $\mathrm{J} / \mathrm{kg} \cdot \mathrm{K}$

$v_{l i}^{r}: \quad$ Relative density of fluid

$q_{l i}^{c}:$ Heat flow, $\mathrm{W} / \mathrm{m}^{2}$

$q_{m i}: \quad$ Total heat flux density, $\mathrm{J} / \mathrm{m}^{2} \cdot \mathrm{s}$

$q_{1 i}: \quad$ Heat flux density of fluid, $\mathrm{J} / \mathrm{m}^{2} \cdot \mathrm{s}$

$\lambda_{s i j}$ : Heat transfer coefficient of rock, $\mathrm{W} / \mathrm{m}^{2} \cdot \mathrm{K}$

$\lambda_{1 i j}$ : Heat transfer coefficient of fluid, $\mathrm{W} / \mathrm{m}^{2} \cdot \mathrm{K}$

$\lambda_{\text {mij }}$ : Equivalent thermal conductivity coefficient, $\mathrm{W} / \mathrm{m}^{2} \cdot \mathrm{K}$

$\varepsilon: \quad$ Strain

$b$ : $\quad$ Three-dimensional force, $\mathrm{N}$

$t$ : $\quad$ Plane vector force, $\mathrm{N}$

$\delta$ : Cake permeability $v$ : $\quad$ Poisson ratio

UCS: Uniaxial compressive strength, $\mathrm{MPa}$

$K$ : Permeability, $\mathrm{mD}$

$\sigma_{1}: \quad$ Maximum main stress, $\mathrm{MPa}$

$\sigma_{3}: \quad$ Minimum main stress, $\mathrm{MPa}$

$\varphi$ : Internal friction angle, $\mathrm{rad}$

$C$ : Cohesive force, $\mathrm{N}$

$\sigma_{\theta}$ : Tangential effective stress in borehole, $\mathrm{MPa}$

$\alpha: \quad$ Effective stress coefficient

$P_{P}$ : $\quad$ Pore pressure, $\mathrm{MPa}$

$S_{t}: \quad$ Tensile strength, $\mathrm{MPa}$

$\sigma_{c}$ : Uniaxial compressive strength, $\mathrm{MPa}$

$p$ : Drilling fluid column pressure, $\mathrm{MPa}$

$p_{w}$ : $\quad$ Borehole pore pressure, $\mathrm{MPa}$

$p_{0}$ : $\quad$ Formation pore pressure.

\section{Conflict of Interests}

The authors declare that there is no conflict of interests regarding the publication of this paper.

\section{Acknowledgments}

The authors gratefully acknowledge the support by the Fundamental Research Funds for the Central Universities (Grant no. 2652011273), the International Scientific and Technological Cooperation projects (Grants nos. 2010DFR70920 and 2011DFR71170), the National Natural Science Foundation of China (Grant no. 51004086), and the open Funds of Key Laboratory on Deep Geo-Drilling Technology, Ministry of Land and Resources (Grant no. NLSD201210). Meanwhile, great thanks also go to former researchers for their excellent works, which was of great help to our academic study.

\section{References}

[1] B. S. Aadnoy, "Introduction to special issue on borehole stability," Journal of Petroleum Science and Engineering, vol. 38, no. 3-4, pp. 79-82, 2003.

[2] B. S. Aadnøy and M. Belayneh, "Elasto-plastic fracturing model for wellbore stability using non-penetrating fluids," Journal of Petroleum Science and Engineering, vol. 45, no. 3-4, pp. 179-192, 2004.

[3] J. S. Bell, "Practical methods for estimating in situ stresses for borehole stability applications in sedimentary basins," Journal of Petroleum Science and Engineering, vol. 38, no. 3-4, pp. 111119, 2003.

[4] Y. Wang and M. B. Dusseault, "A coupled conductive-convective thermo-poroelastic solution and implications for wellbore stability," Journal of Petroleum Science and Engineering, vol. 38, no. 3-4, pp. 187-198, 2003.

[5] M. D. Zoback, C. A. Barton, M. Brudy et al., "Determination of stress orientation and magnitude in deep wells," International Journal of Rock Mechanics and Mining Sciences, vol. 40, no. 7-8, pp. 1049-1076, 2003.

[6] A. M. Al-Ajmi and R. W. Zimmerman, "Stability analysis of vertical boreholes using the Mogi-Coulomb failure criterion," International Journal of Rock Mechanics and Mining Sciences, vol. 43, no. 8, pp. 1200-1211, 2006. 
[7] T. Al-Bazali, J. Zhang, M. E. Chenevert, and M. M. Sharma, "Factors controlling the compressive strength and acoustic properties of shales when interacting with water-based fluids," International Journal of Rock Mechanics and Mining Sciences, vol. 45, no. 5, pp. 729-738, 2008.

[8] Y. M. Chen, M. E. Chenevert, and M. M. Sharma, "Chemicalmechanical boreholebore instability model in shale," Journal of Petroleum Sciences and Technology, vol. 38, no. 34, pp. 167-176, 2003.

[9] J. C. Roegiers, "Well modeling: an overview," Oil and Gas Science and Technology, vol. 57, no. 5, pp. 569-577, 2002.

[10] E. Fjar, R. M. Holt, A. M. Raaen, R. Risnes, and P. Horsrud, Petroleum Related Rock Mechanics, Elsevier, 2nd edition, 2008.

[11] B. H. Wei, X. F. Lu, B. Y. Wang, J. Deng, and C. Liu, "Law of temperature influence on wellbore stability in hot well," Drilling Fluid and Completion Fluid, vol. 21, no. 6, pp. 15-18, 2004.

[12] V. Maury and A. Guenot, "Practical advantages of mud cooling systems for drilling," SPE Drillings \& Completion, vol. 10, no. 1, pp. 42-48, 1995.

[13] H. F. Wang, B. P. Bonner, S. R. Carlson, B. J. Kowallis, and H. C. Heard, "Thermal stress cracking in granite," Journal of Geophysical Research, vol. 94, no. 2, pp. 1745-1758, 1989.

[14] Y. Chen, X. D. Wu, and F. Q. Zhang, "Tests on hot cracking of rock," Chinese Science Bulletin, vol. 44, no. 8, pp. 880-883, 1999.

[15] N. Zhang, Y. Zhao, Z. Wan, F. Dong, and Z. Feng, "Experimental research on seepage laws of granite under thermal cracking action with 3D stress," Chinese Journal of Rock Mechanics and Engineering, vol. 29, no. 1, pp. 118-123, 2010.

[16] R. Narayanasamy, D. Bar, and A. Milne, "Wellbore instability predictions within the cretaceous mudstones, clair field, west of Shetlands," in Proceedings of the Offshore Europe Oil and Gas Conference and Exhibition (OE '09), pp. 847-858, Aberdeen, UK, September 2009.

[17] P. A. Nawrocki, M. B. Dusseault, and R. K. Bratli, "Assessment of some semi-analytical models for non-linear modeling of borehole stresses," International Journal of Rock Mechanical \& Mining Science, vol. 35, no. 4-5, pp. 522-531, 2002.

[18] C. F. Tsang, Coupled Processes Associated with Nuclear Waste Repositories, Academic Press, New York, NY, USA, 1987.

[19] L. Jing and X. Feng, "Numerical modeling for coupled thermohydro-mechanical and chemical processes (THMC) of geological media-international and Chinese experiences," Chinese Journal of Rock Mechanics and Engineering, vol. 22, no. 10, pp. 1704-1715, 2003.

[20] J. A. Hudson, O. Stephansson, J. Andersson, C.-F. Tsang, and L. Jing, "Coupled T-H-M issues relating to radioactive waste repository design and performance," International Journal of Rock Mechanics and Mining Sciences, vol. 38, no. 1, pp. 143-161, 2001.

[21] C.-F. Tsang, L. Jing, O. Stephansson, and F. Kautsky, "The DECOVALEX III project: a summary of activities and lessons learned," International Journal of Rock Mechanics and Mining Sciences, vol. 42, no. 5-6, pp. 593-610, 2005.

[22] A. Millard, A. Rejeb, M. Chijimatsu et al., "Numerical study of the THM effects on the near-field safety of a hypothetical nuclear waste repository-BMT1 of the DECOVALEX III project-part 2: effects of THM coupling in continuous and homogeneous rocks," International Journal of Rock Mechanics and Mining Sciences, vol. 42, no. 5-6, pp. 731-744, 2005.

[23] Q. Wang, Y. Zhou, Y. Tang, and Z. Jiang, "Analysis of effect factor in shale wellbore stability," Chinese Journal of Rock Mechanics and Engineering, vol. 31, no. 1, pp. 171-179, 2012.
[24] Q. Wang, Y. C. Zhou, G. Wang, H. W. Jiang, and Y. S. Liu, "A fluid-solid-chemistry coupling model for shale boreholebore stability," Petroleum Exploration and Development, vol. 39, no. 4, pp. 475-480, 2012.

[25] J. Rutqvist, X. T. Feng, J. A. Hudson et al., "Multiple-code bench mark simulation study of coupled THMC processes in the excavation disturbed zone associated with geological nuclear waste repositories," in Proceedings of the 2nd International Conference on Coupled T-H-M-C Processes in Geosystems: Fundamentals, Modeling, Experiments and Applications, pp. 22-24, Nanjing, China, 2006.

[26] J. Feng and J. Ding, "Radiator optimization of LED street lamp based on parameterized language APDL of ANSYS," Semiconductor Photonics and Technology, vol. 16, no. 2-3, pp. 8892, 2010.

[27] X. Yin, J. Li, and C. Wu, "ANSYS implementation of damping solvent stepwise extraction method for nonlinear seismic analysis of large 3-D structures," Soil Dynamics and Earthquake Engineering, vol. 44, pp. 139-152, 2013.

[28] Y. H. Lu, M. Chen, Y. Jin, X. Q. Teng, W. Wu, and X. Q. Liu, "Experimental study of strength properties of deep mudstone under drilling fluid soaking," Chinese Journal of Rock Mechanics and Engineering, vol. 31, no. 7, pp. 1399-1405, 2012.

[29] S. Jia, X. Ran, Y. Wang et al., "Fully coupled thermal-hydraulicmechanical model and finite element analysis for deformation porous media," Chinese Journal of Rock Mechanics and Engineering, vol. 31, supplement 2, pp. 3547-3556, 2012.

[30] D. W. Marshall and R. G. Bentsen, "A computer model to determine the temperature distributions in a wellbore," The Journal of Canadian Petroleum Technology, vol. 21, no. 1, pp. 6375, 1982.

[31] C. Yan, J. Deng, and B. Yu, "Wellbore stability in oil and gas drilling with chemical-mechanical coupling," The Scientific World Journal, vol. 2013, Article ID 720271, 9 pages, 2013. 

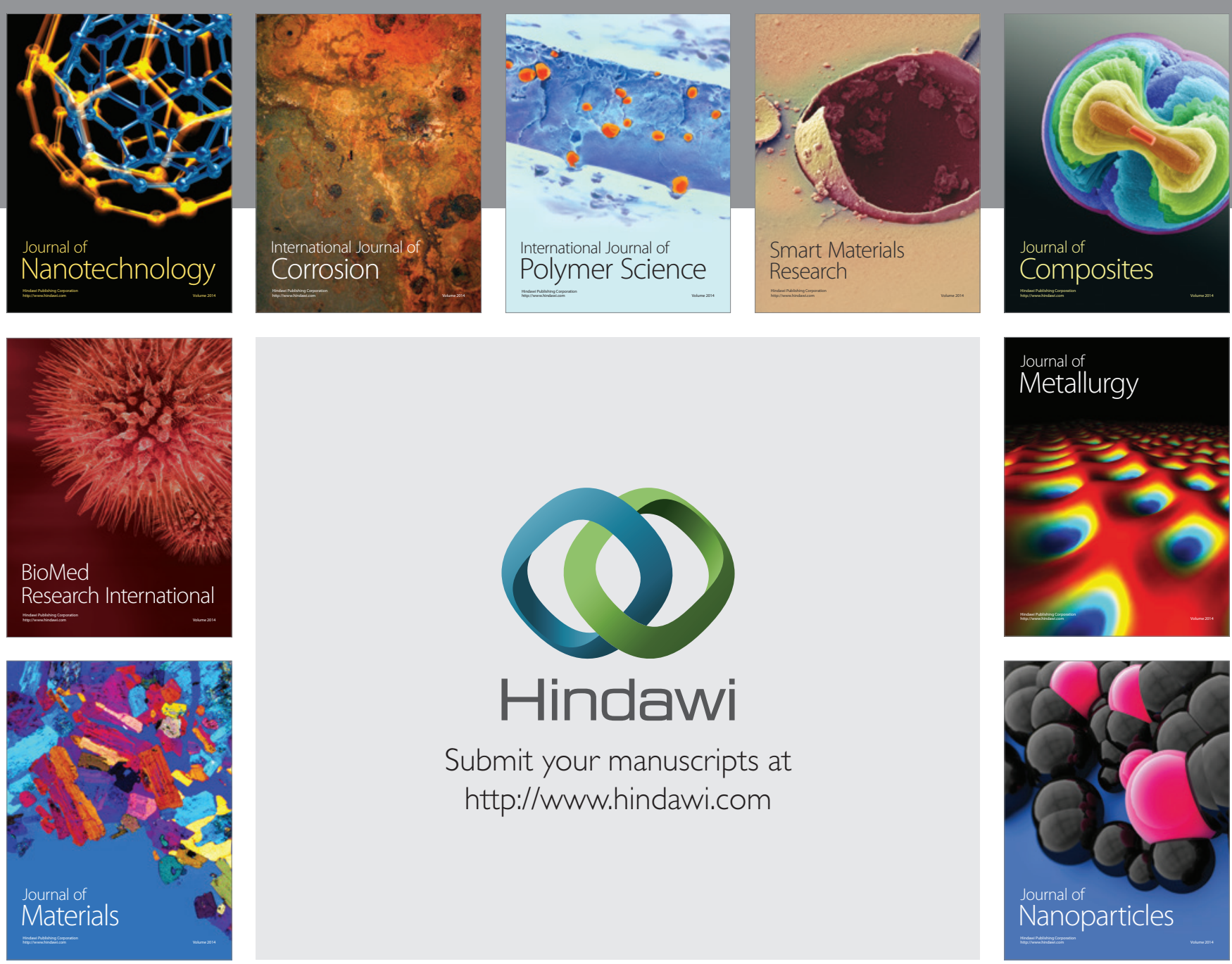

Submit your manuscripts at http://www.hindawi.com
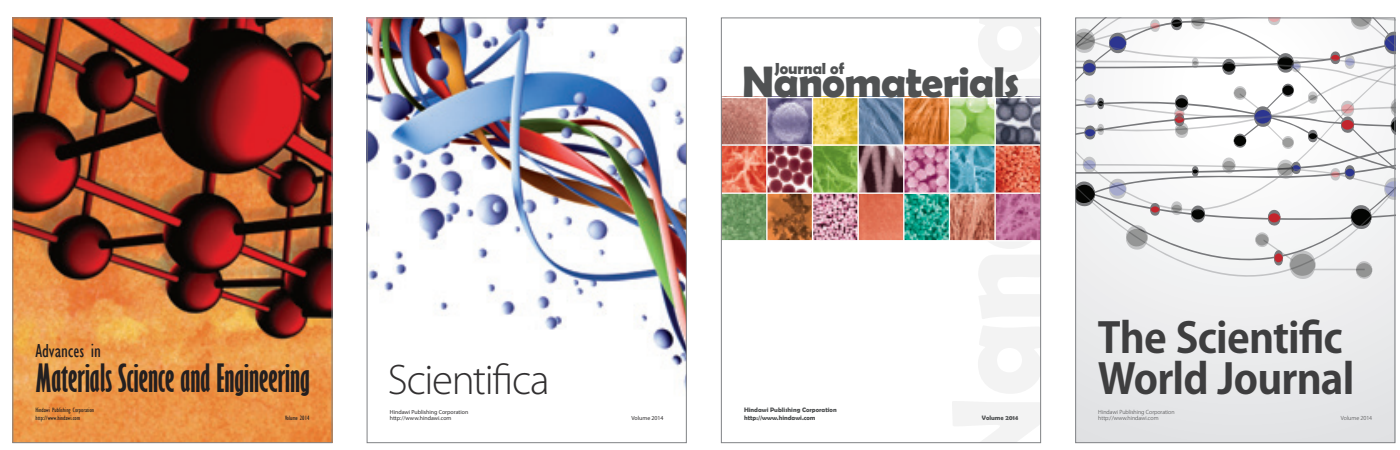

\section{The Scientific World Journal}
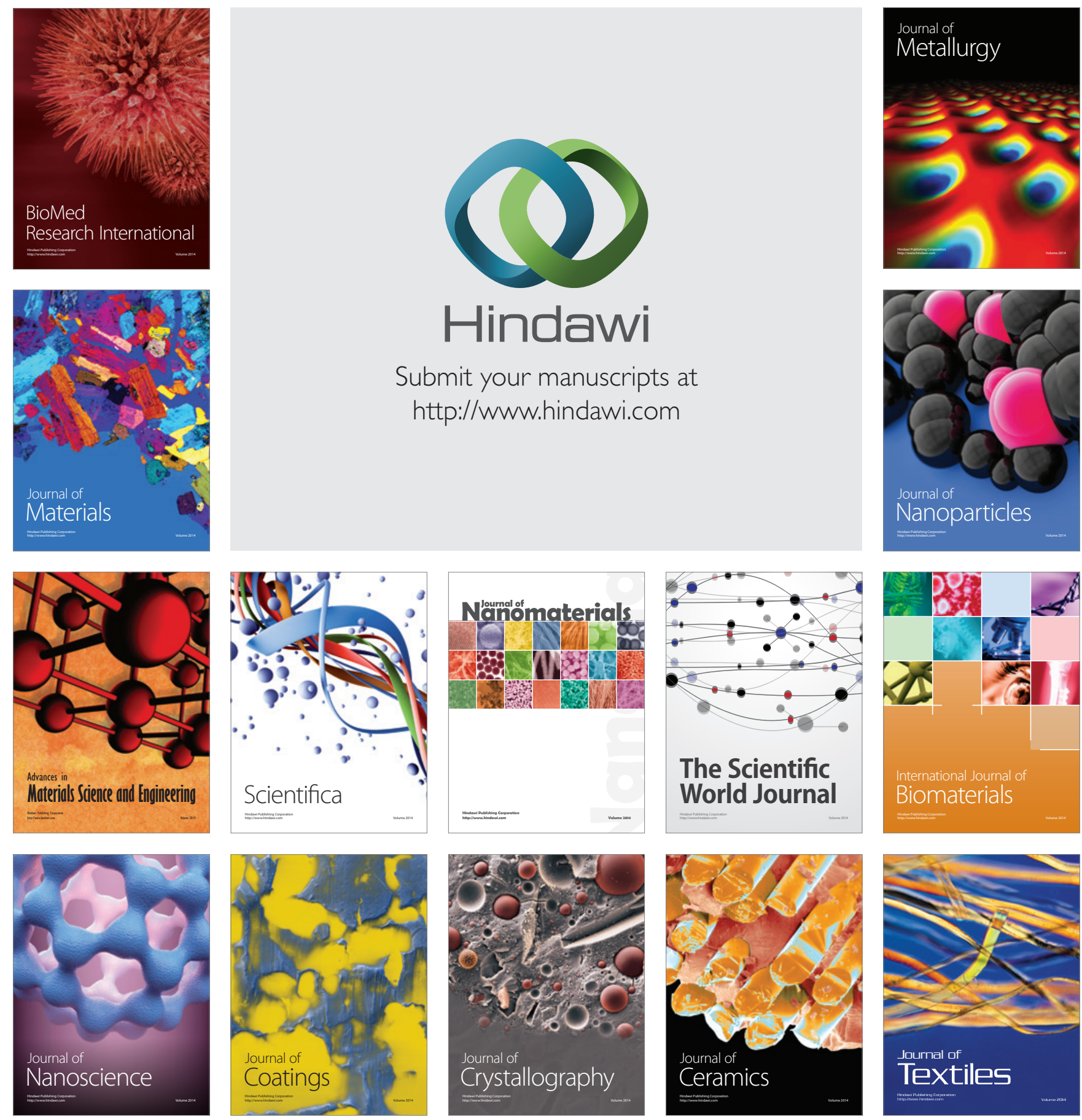